\title{
Separation and Identification of DMPO Adducts of Oxygen-Centered Radicals Formed from Organic Hydroperoxides by HPLC-ESR, ESI-MS and MS/MS
}

\author{
Qiong Guo, Steven Y. Qian, and Ronald P. Mason \\ Laboratory of Pharmacology and Chemistry, National Institute of Environmental Health Sciences, \\ National Institutes of Health, Research Triangle Park, North Carolina, USA
}

\begin{abstract}
Many electron spin resonance (ESR) spectra of 5,5-dimethyl-1-pyrroline $N$-oxide (DMPO) radical adducts from the reaction of organic hydroperoxides with heme proteins or $\mathrm{Fe}^{2+}$ were assigned to the adducts of DMPO with peroxyl, alkoxyl, and alkyl radicals. In particular, the controversial assignment of DMPO/peroxyl radical adducts was based on the close similarity of their ESR spectra to that of the DMPO/superoxide radical adduct in conjunction with their insensitivity to superoxide dismutase, which distinguishes the peroxyl adducts from the DMPO/superoxide adduct. Although recent reports assigned the spectra suggested to be $\mathrm{DMPO} /$ peroxyl radical adducts to the DMPO/methoxyl adduct based on independent synthesis of the adduct and / or ${ }^{17} \mathrm{O}$-labeling, ${ }^{17} \mathrm{O}$-labeling is extremely expensive, and both of these assignments were still based on hyperfine coupling constants, which have not been confirmed by independent techniques. In this study, we have used online high performance liquid chromatography (HPLC or LC)/ESR, electrospray ionization-mass spectrometry (ESIMS) and tandem mass spectrometry (MS/MS) to separate and directly characterize DMPO oxygen-centered radical adducts formed from the reaction of $\mathrm{Fe}^{2+}$ with $t$-butyl or cumene hydroperoxide. In each reaction system, two DMPO oxygen-centered radical adducts were separated and detected by online LC/ESR. The first DMPO radical adduct from both systems showed identical chromatographic retention times $\left(t_{R}=9.6 \mathrm{~min}\right)$ and hyperfine coupling constants $\left(a^{\mathrm{N}}=14.51 \mathrm{G}, a^{\mathrm{H}}{ }_{\beta}=10.71 \mathrm{G}\right.$, and $\left.a^{\mathrm{H}}{ }_{\gamma}=1.32 \mathrm{G}\right)$. The ESI-MS and MS/MS spectra demonstrated that this radical was the DMPO/methoxyl radical adduct, not the peroxyl radical adduct as was thought at one time, although its ESR spectrum is nearly identical to that of the DMPO/superoxide radical adduct. Similarly, based on their MS/MS spectra, we verified that the second adducts $\left(a^{\mathrm{N}}=14.86 \mathrm{G}\right.$ and $a^{\mathrm{H}}{ }_{\beta}=16.06 \mathrm{G}$ in the reaction system containing $t$-butyl hydroperoxide and $a^{\mathrm{N}}=14.60 \mathrm{G}$ and $a^{\mathrm{H}}{ }_{\beta}{ }^{\beta}=15.61 \mathrm{G}$ in the reaction mixture containing cumene hydroperoxide), previously assigned as DMPO adducts of $t$-butyloxyl and cumyloxyl radical, were indeed from trapping $t$-butyloxyl and cumyloxyl radicals, respectively. (J Am Soc Mass Spectrom 2003, 14, 862-871) (c) 2003 American Society for Mass Spectrometry
\end{abstract}

$\mathrm{F}$ ree radicals are known to cause damage to biomembranes, proteins and other biomolecules and they are suspected to mediate process leading to some human diseases [1-7]. Short-lived free radicals have customarily been detected using spin traps, which react with the radicals to form relatively stable radical adducts. With the spin-trapping technique, determination of the structures of radical adducts is based mainly on the hyperfine coupling constants of the ESR spectra, but the structural information provided by hyperfine coupling constants is limited.

Published online June 25, 2003

Address reprint requests to Dr. Qiong Guo, Laboratory of Pharmacology and Chemistry, National Institute of Environmental Health Sciences, National Institutes of Health, P. O. Box 12233, Research Triangle Park, NC 27709. E-mail: guo1@niehs.nih.gov
For instance, DMPO is a widely used nitrone spin trap, which can trap not only carbon-centered but also oxygen-centered radicals generated in chemical and biochemical systems [8-10]. The hyperfine coupling constants of DMPO radical adducts are, in general, particularly useful for distinguishing the trapped radicals such as the DMPO/superoxide anion radical adduct from the DMPO/hydroxyl radical adduct. However, the determination of the structures of other DMPO oxygen-centered radical adducts is based mainly on the limited information obtained from their hyperfine coupling constants and the similarity of their ESR spectra to that of the superoxide or hydroxyl radical adduct. The structural information provided by hyperfine coupling constants is limited, and the assignment based on the similarity of their ESR spectra to radical adducts of the 
(a)

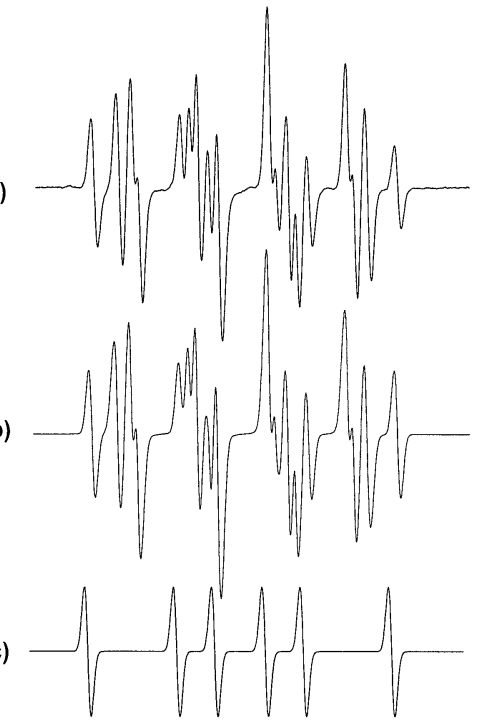

(d)

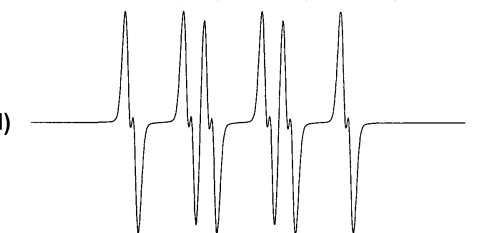
DMPO/OOR' DMPO/R
$t$-BuOOH (1.0 mM) DMPO $(50 \mathrm{mM})$ $\mathrm{Fe}^{2+}(0.5 \mathrm{mM})$

Composite simulation

Computer simulation

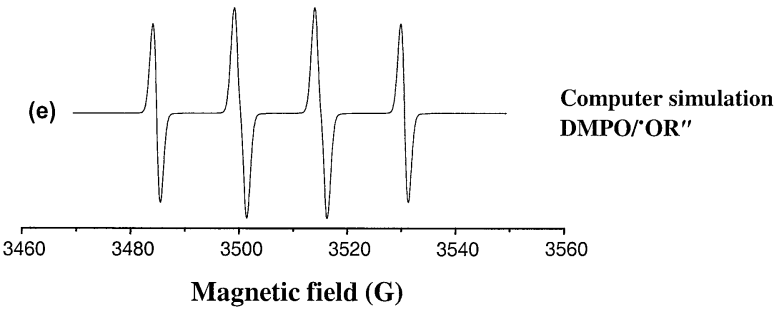

Figure 1. Computer simulation and deconvolution of the ESR spectrum obtained from the reaction of $t$-butyl hydroperoxide with $\mathrm{Fe}^{2+}$. (a) An ESR spectrum obtained from a reaction mixture containing $1.0 \mathrm{mM} t-\mathrm{BuOOH}, 50 \mathrm{mM}$ DMPO, and $0.5 \mathrm{mM}$ ferrous sulfate. (b) Composite simulation of spectrum $a$. (c) Simulated spectrum for DMPO/carbon-centered radical adduct: Line width, $0.64 \mathrm{G}$; line shape, $0 \%$ Lorentzian and $100 \%$ Gaussian; mole ratio, 0.13. (d) Simulated spectrum for DMPO/OR': Line width, 0.65 G; line shape, $25 \%$ Lorentzian; and mole ratio, 0.60. (e) Simulated spectrum for DMPO/OR": Line width, $0.73 \mathrm{G}$; line shape, 11\% Lorentzian; mole ratio, 0.27 . Spectrometer conditions were as follows: Microwave power, $20 \mathrm{~mW}$; microwave frequency, 9.8 $\mathrm{GHz}$; modulation amplitude, $1.0 \mathrm{G}$; scan width, $80 \mathrm{G}$; time constant, $164 \mathrm{~ms}$; conversion time, $82 \mathrm{~ms}$; gain, $5.0 \times 10^{4}$.

known structures sometimes is controversial. For example, in reactions of organic hydroperoxides such as $t$-butyl hydroperoxide $(t$-BuOOH) or cumene hydroperoxide (CumOOH) with hemoproteins, ESR spectra were first assigned to the DMPO adducts with peroxyl, alkoxyl, and alkyl radicals [11-18]. Initial reports identified DMPO/superoxide like spectra as DMPO/peroxyl radical adducts of the parent hydroperoxide [1115], while later investigators assigned them as DMPO/ methylperoxyl [16-18]. In fact, the assignment of $\mathrm{DMPO} /$ peroxyl radical adducts was based only on the very close similarity of their ESR spectra to the DMPO/ superoxide radical adduct in conjunction with their (a)

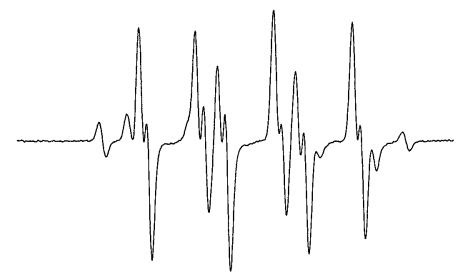

CumOOH (0.68 mM) DMPO (50 $\mathrm{mM})$

$\mathrm{Fe}^{2+}(0.5 \mathrm{mM})$

(b)

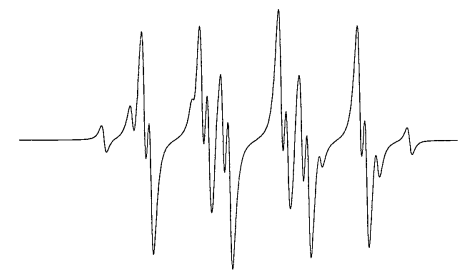

Composite simulation

(c)

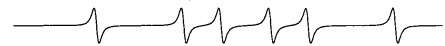

Computer simulation DMPO/R

Computer simulation

(d)

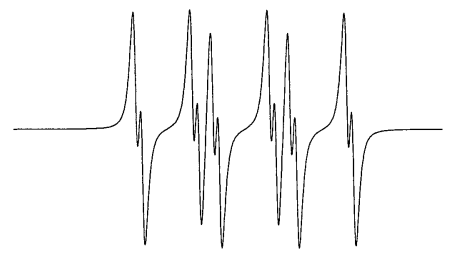

DMPO/'OR'

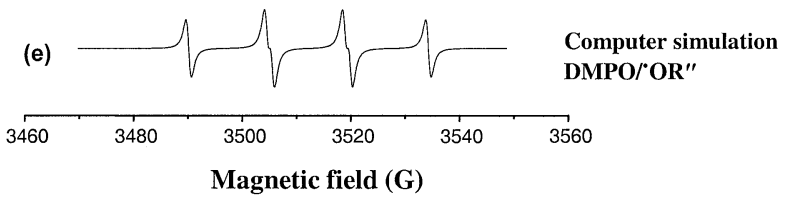

Figure 2. Computer simulation and deconvolution of the ESR spectrum obtained from the reaction of cumene hydroperoxide with $\mathrm{Fe}^{2+}$. (a) An ESR spectrum obtained from a reaction mixture containing $0.68 \mathrm{mM}$ CumOOH, $50 \mathrm{mM}$ DMPO, and $0.5 \mathrm{mM}$ ferrous sulfate. (b) Composite simulation of Spectrum a. (c) Simulated spectrum for DMPO/carbon-centered radical adduct: Line width, $0.64 \mathrm{G}$; line shape, $0 \%$ Lorentzian and 100\% Gaussian; mole ratio, 0.05. (d) Simulated spectrum for DMPO/OR': Line width, $0.65 \mathrm{G}$; line shape, $25 \%$ Lorentzian; mole ratio, 0.85 . (e) Simulated spectrum for DMPO/OR": Line width, $0.86 \mathrm{G}$; line shape, $100 \%$ Lorentzian; mole ratio, 0.10 . Instrumental parameters are the same as above.

insensitivity to superoxide dismutase, which excludes the $\mathrm{DMPO} /$ superoxide adduct. In other recent reports $[19,20]$, the same adducts were reassigned as the $\mathrm{DMPO} /$ methoxyl adduct based on independent synthesis and/or ${ }^{17} \mathrm{O}$-labeling. Although ${ }^{17} \mathrm{O}$-labeling can give some such information $[19,20]$, it is extremely expensive, and will be of little help in identifying the detailed structures of oxygen-centered radical adducts formed from hydroperoxides of fatty acids. Moreover, both of these assignments are still based on hyperfine coupling constants, which have not been confirmed by independent techniques.

In several recent studies, a unique technique has been developed to isolate and identify radical adducts of spin traps more precisely using high performance liquid chromatography (HPLC)/ESR, LC/MS, and 

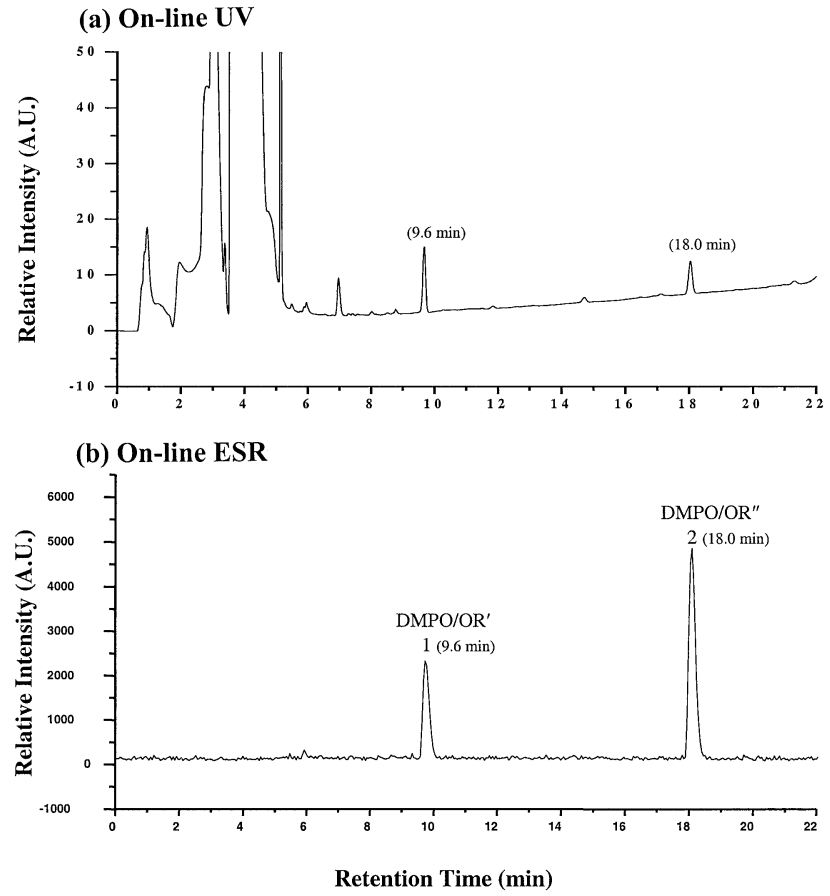

Figure 3. On-line LC/ESR detection of DMPO radical adducts obtained from the reaction of $\mathrm{Fe}^{2+}$ with $t$-butyl hydroperoxide. The reaction mixture containing $1.0 \mathrm{mM} \mathrm{t}-\mathrm{BuOOH}$ (dissolved in $0.01 \% t$-butanol), $50 \mathrm{mM}$ DMPO, and $0.5 \mathrm{mM}$ ferrous sulfate was incubated at room temperature for $1 \mathrm{~min}$. Peaks 1 and 2 correspond to the adducts of DMPO/OR' and DMPO/OR" in Figure 1, respectively. LC and ESR parameters are described in the Experimental section.

MS/MS [21-25]. This technique, online LC/ESR combined with mass spectrometry, has been used to identify carbon-centered radical adducts of peroxidation of fatty acids with the spin trap POBN, but no oxygencentered adducts were detected. Importantly, DMPO adducts of oxygen-centered radicals from lipid peroxidation have been detected by ESR, but the detailed structures which have been assigned using hyperfine coupling constants alone are uncertain. Thus far only a few DMPO radical adducts have been characterized using mass spectrometry [26-28].

In this study, we have successfully used online LC/ESR to separate a number of ESR-active DMPO adducts of radicals formed from the reaction of $\mathrm{Fe}^{2+}$ with $t-\mathrm{BuOOH}$ or $\mathrm{CumOOH}$, and established their identities directly by ESI-MS and MS/MS analysis, which may make it possible to unambiguously identify the DMPO oxygen-centered adducts produced by peroxidation of fatty acids and further understand the mechanisms of the free radical chain reaction of lipid peroxidation.

\section{Experimental}

\section{Chemicals}

Acetonitrile (ACN) and water, HPLC grade, were purchased from Krackeler Southeast Scientific (Durham,

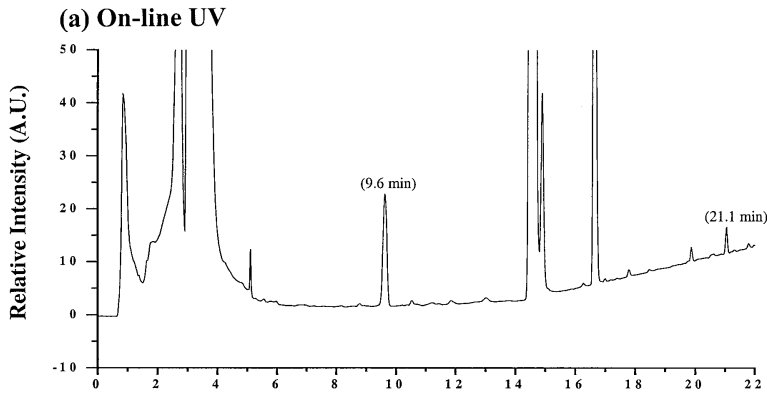

(b) On-line ESR

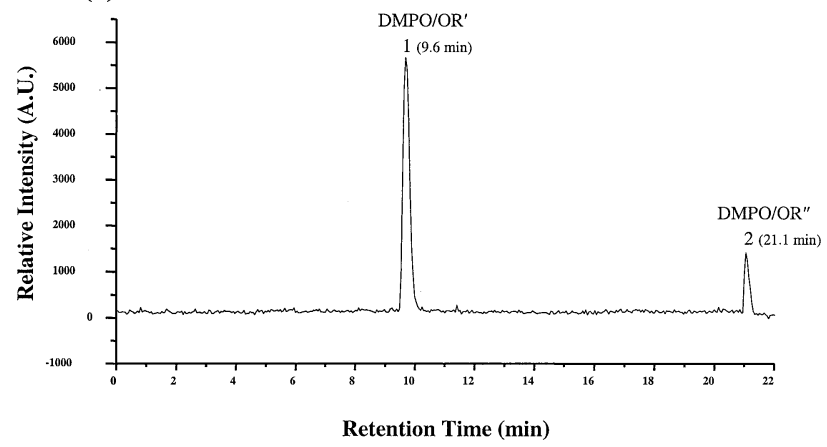

Figure 4. On-line LC/ESR detection of DMPO radical adducts obtained from the reaction of $\mathrm{Fe}^{2+}$ with cumene hydroperoxide. The reaction mixture containing $0.68 \mathrm{mM} \mathrm{CumOOH}$ (dissolved in $2.5 \%$ t-butanol), $50 \mathrm{mM} \mathrm{DMPO}$, and $0.5 \mathrm{mM}$ ferrous sulfate was incubated at room temperature for $1 \mathrm{~min}$. Peaks 1 and 2 correspond to the adducts of DMPO/OR' and DMPO/OR" in Figure 2, respectively. LC and ESR parameters are described in the Experimental section.

$\mathrm{NC}$ ). CumOOH and tetrahydrofuran (THF) (HPLC grade) were obtained from Aldrich Chemical Company (Milwaukee, WI). Methanol (HPLC grade) was from EM Science (Gibbstown, NJ). $t$-BuOOH, tert-butanol, and glacial acetic acid (HOAc) were purchased from Sigma Chemical Company (St. Louis, MO). Hydrogen peroxide was from Fisher Scientific (Fair Lawn, NJ). Acrodisc $13 \mathrm{~mm}$ syringe filters with $0.2 \mu \mathrm{m}$ nylon membrane (HPLC certified) were obtained from the Pall Gelman Laboratory (Ann Arbor, MI). DMPO (high purity, $\geq 99 \%$ ) was purchased from Alexis Biochemicals (San Diego, CA), used after filtered through the filters mentioned above. All other chemicals used were of analytical grade.

\section{Chemical Reactions}

The reaction mixture containing $1.0 \mathrm{mM} t-\mathrm{BuOOH}$ (dissolved in $0.01 \% t$-butanol) or $0.68 \mathrm{mM} \mathrm{CumOOH}$ (dissolved in 2.5\% $t$-butanol), $50 \mathrm{mM} \mathrm{DMPO}$, and 0.5 $\mathrm{mM}$ ferrous sulfate was incubated at room temperature for $1 \mathrm{~min}$. The reaction mixture was either transferred to a $100 \mu \mathrm{L}$ capillary which was inserted into the cavity of ESR for ESR measurements, or filtered, and injected onto the HPLC column for online LC/ESR measurements. 


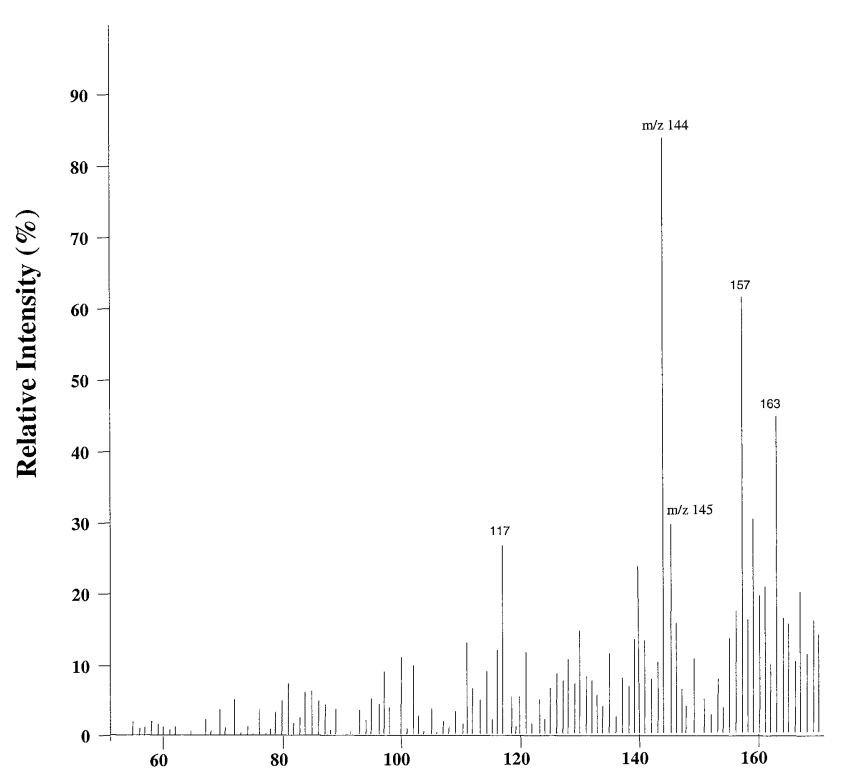

(a)

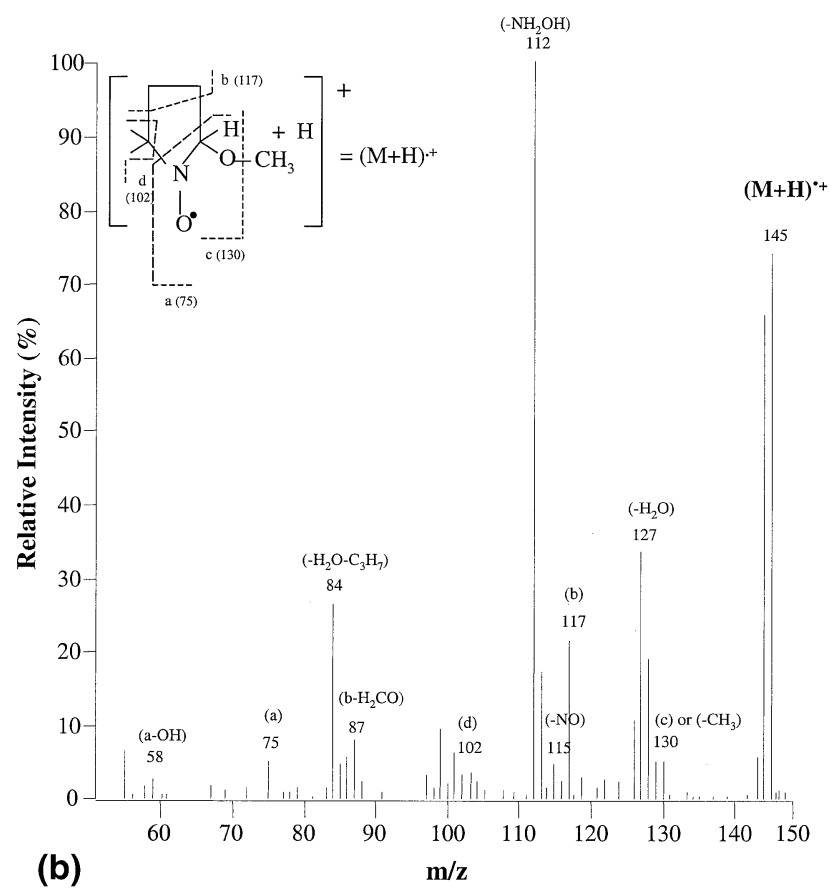

Figure 5. The ESI-MS (a) and MS/MS (b) spectra of the protonated molecule of $\mathrm{DMPO} / \mathrm{OCH}_{3}$ adduct $\left[\left(\mathrm{DMPO} / \mathrm{OCH}_{3}+\mathrm{H}\right)^{\cdot+}\right.$, $m / z=145]$ in the reaction of $\mathrm{Fe}^{2+}$ with $t$-butyl or cumene hydroperoxide. The analysis obtained from LC/ESR separation was infused into the mass spectrometer at $5 \mu \mathrm{L} / \mathrm{min}$ using a 500 $\mu \mathrm{L}$ syringe associated with a syringe pump. Instrumental conditions are described in the Experimental section.

\section{ESR Spin Trapping Measurements}

ESR spectra were obtained with a Bruker ElexSys E500 spectrometer equipped with a super high $Q$ cavity operating at $9.78 \mathrm{GHz}$ and room temperature. The ESR spectrometer settings were as follows: modulation frequency, $100 \mathrm{kHz}$; modulation amplitude, $1.0 \mathrm{G}$; micro- wave power, $20 \mathrm{~mW}$; receiver gain, $5 \times 10^{4}$; time constant, $164 \mathrm{~ms}$; conversion time, $82 \mathrm{~ms}$; magnetic field scan, $80 \mathrm{G}$.

\section{Online LC/ESR Measurements}

An online LC/ESR system was used to separate and detect active DMPO radical adducts, which were monitored with both UV absorption at $254 \mathrm{~nm}$ and twodimensional ESR scans (magnetic field versus time). This system consisted of a Hewlett-Packard 1100 series HPLC system and a Bruker ElexSys E500 spectrometer. The outlet of the UV detector was connected to the highly sensitive AquaX ESR cell with Red PEEK HPLC tubing (0.005 inch i.d.).

LC separations were performed on C-18 columns (Hewlett Packard ZORBAX Eclipse XDB, $4.6 \times 75 \mathrm{~mm}$, $3.5 \mu \mathrm{m}$ ) equilibrated with solvent $\mathrm{A}$, which consisted of $\mathrm{H}_{2} \mathrm{O}$ containing $0.1 \%$ HOAc. $150 \mu \mathrm{L}$ of the reaction mixture was typically injected onto the HPLC column and eluted at a $1.0 \mathrm{ml} / \mathrm{min}$ flow rate with gradient elutions of either (1) $0-20 \mathrm{~min}: 0-40 \%$ of solvent B (ACN:THF (9:1) with 0.1\% HOAc) and (2) 20-25 min: $40-90 \%$ of solvent $B$ for the reaction systems containing $t-\mathrm{BuOOH}$, or (1) $0-12$ min: $0-24 \%$ of solvent B (ACN: THF (9:1) with $0.1 \%$ HOAc) and (2) $12-25$ min: $24-90 \%$ of solvent $\mathrm{B}$ for the reaction systems containing $\mathrm{Cu}-$ $\mathrm{mOOH}$.

The ESR spectrometer settings were as follows: modulation frequency, $100 \mathrm{kHz}$; modulation amplitude, 2.0 G; microwave power, $20 \mathrm{~mW}$; receiver gain, $2 \times 10^{5}$; time constant, $5.12 \mathrm{~ms}$; conversion time, $5.12 \mathrm{~ms}$; sweep time, $2.6 \mathrm{~s}$, number of points, 512; number of scans, 2; magnetic field scan, $60 \mathrm{G}$.

Electrospray Ionization Mass Spectrometry (ESI/ MS) and Tandem Mass Spectrometry (MS/MS) Analysis

The peaks with corresponding absorptions in both the UV trace and the ESR trace were collected according to their retention times and subjected to mass spectrometric analysis. ESI mass spectra and MS/MS spectra were obtained on a Finnigan LCQ ion trap mass spectrometer using an electrospray ionization and Finnigan Xcalibur software (version 1.2). MS conditions were: sheath gas (nitrogen used) at a flow rate of $35 \%$ (arbitrary units); capillary temperature, $50-120^{\circ} \mathrm{C}$; capillary voltage, $17 \mathrm{~V}$; and spray voltage, 3.0-5.0 kV. MS/MS experiments were carried out using Helium as collision gas. Collision energies were adjusted (typically 20-30\%, 100\% collision energy corresponds to $5 \mathrm{~V}$ peak to peak) in order to get maximum structural information for each experiment. Samples were infused into the mass spectrometer at $5 \mu \mathrm{L} / \mathrm{min}$ by a syringe pump. 
Pathway 1:

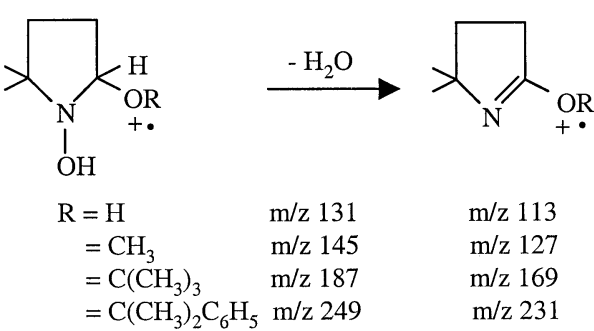

Pathway 2:

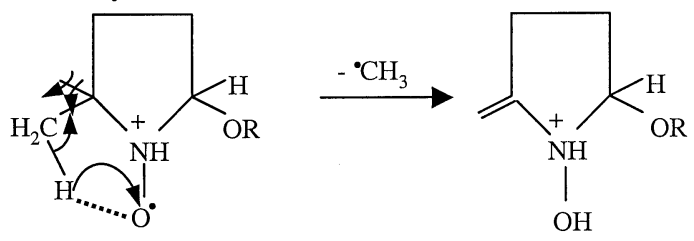

$$
\begin{aligned}
& \mathrm{R}=\mathrm{H}: \quad \mathrm{m} / \mathrm{z} 131 \quad \mathrm{~m} / \mathrm{z} 116 \\
& =\mathrm{CH}_{3} \quad \mathrm{~m} / \mathrm{z} 145 \quad \mathrm{~m} / \mathrm{z} 130 \\
& =\mathrm{C}\left(\mathrm{CH}_{3}\right)_{3} \quad \mathrm{~m} / \mathrm{z} 187 \quad \mathrm{~m} / \mathrm{z} 172 \\
& =\mathrm{C}\left(\mathrm{CH}_{3}\right)_{2} \mathrm{C}_{6} \mathrm{H}_{5} \mathrm{~m} / \mathrm{z} 249 \quad \mathrm{~m} / \mathrm{z} 234
\end{aligned}
$$

Pathway 3:

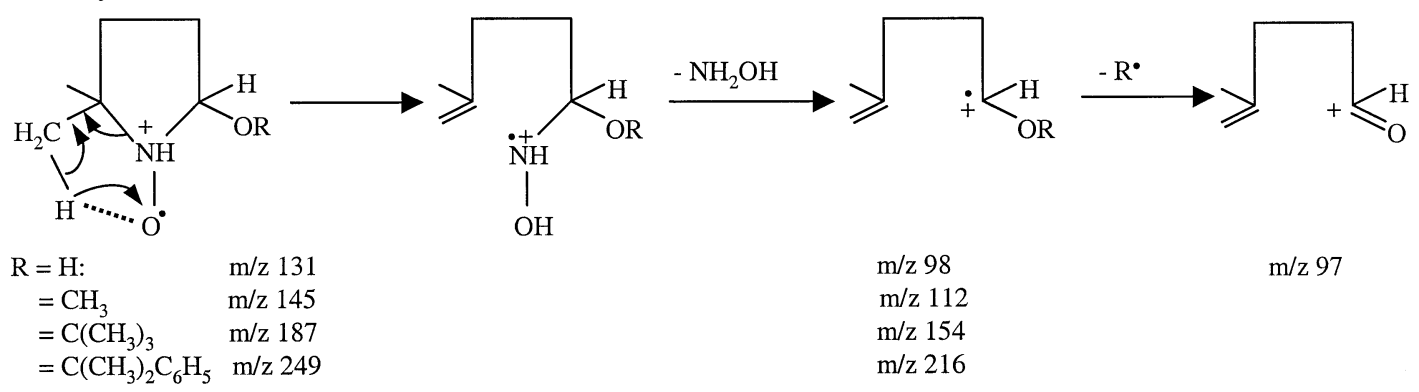

Pathway 4 (or pathway a):

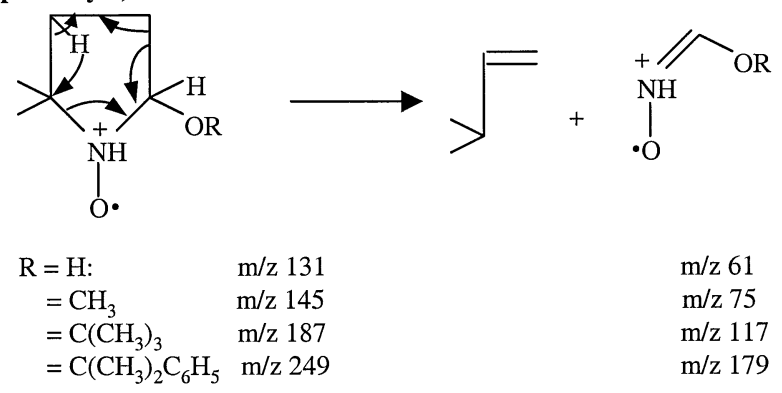

Pathway 5 (or pathway b):

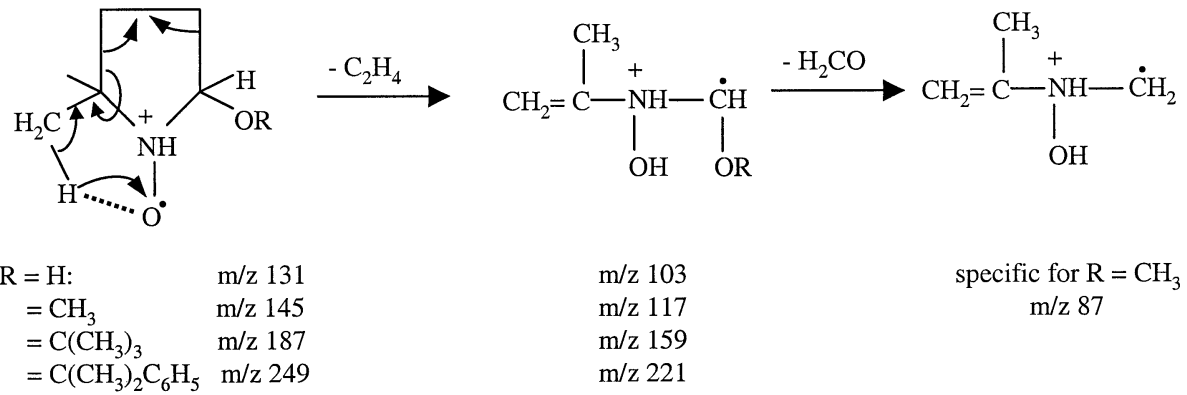

Scheme 1. Proposed fragmentation pathways of the protonated ions of $m / z 131,145,187$, and 249.

\section{Results and Discussion}

Spin Trapping of Radicals Generated from the Reaction of Organic Hydroperoxides with $\mathrm{Fe}^{2+}$ in the Presence of DMPO

The ESR spin-trapping technique was employed to detect free radical production during the reaction between $t$ - $\mathrm{BuOOH}$ (or $\mathrm{CumOOH}$ ) and $\mathrm{Fe}^{2+}$. When $1.0 \mathrm{mM}$
$t$-BuOOH was reacted with $0.5 \mathrm{mM} \mathrm{Fe}^{2+}$ in the presence of $50 \mathrm{mM}$ DMPO, a mixture of three radical adducts was detected (Figure 1a). A similar ESR spectrum was also obtained when $0.68 \mathrm{mM} \mathrm{CumOOH}$ replaced $t$ $\mathrm{BuOOH}$ (Figure 2a). The spectra were similar to those observed in previous studies of the reaction of $t$-BuOOH or $\mathrm{CumOOH}$ with heme proteins [11-18].

The composite simulated spectra in Figures $1 \mathrm{~b}$ and 


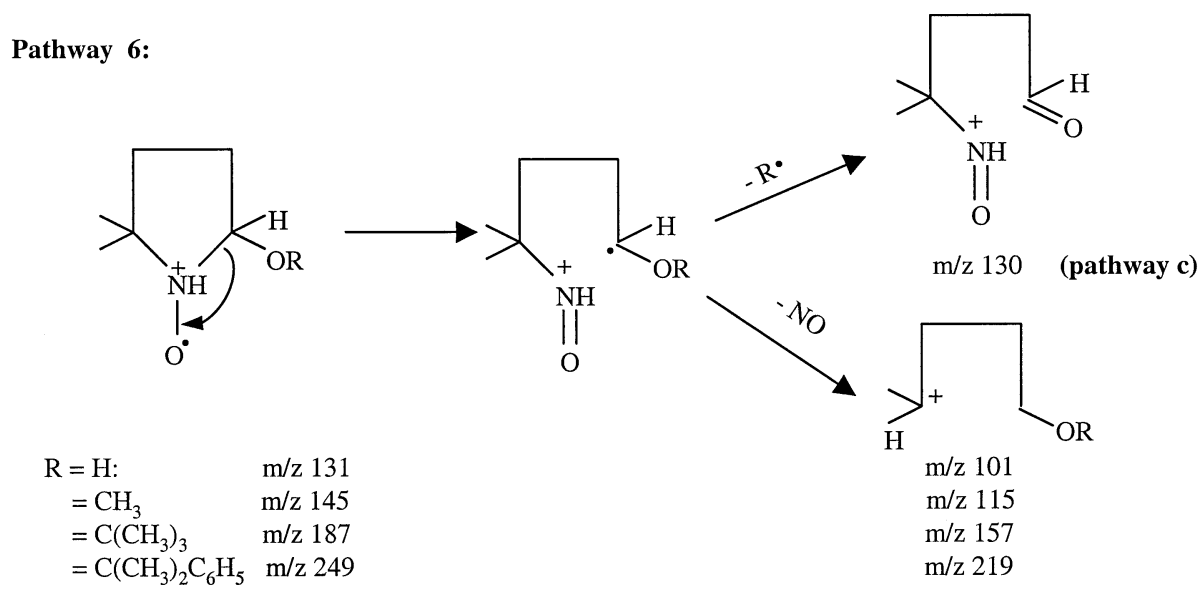

Pathway 7 (or pathway d):

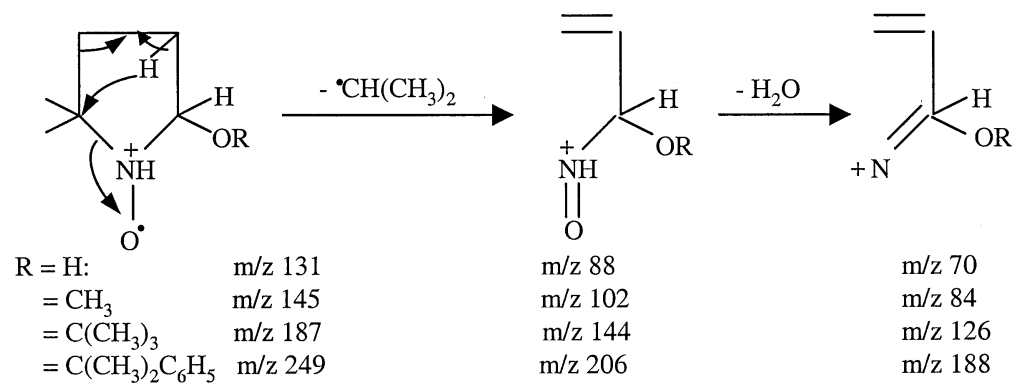

Specific for $\mathrm{R}=\mathrm{H}$

(1)

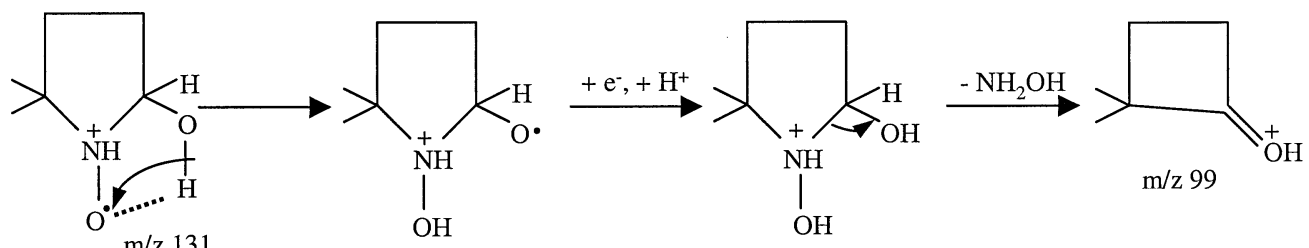

(2)

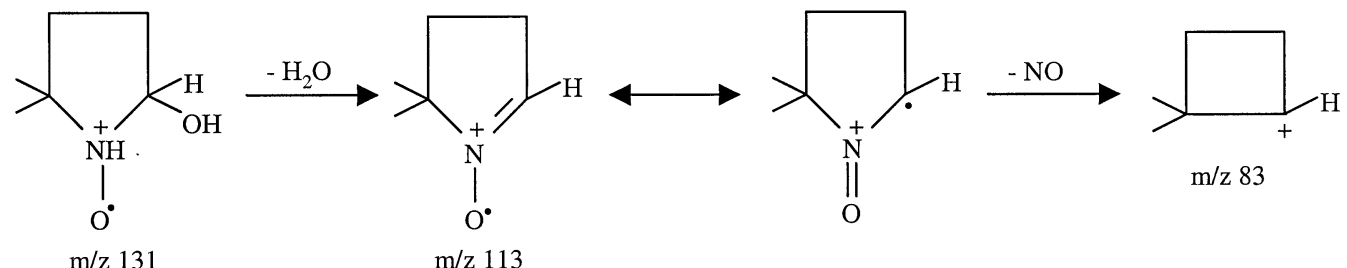

Scheme 1. Continued.

$2 \mathrm{~b}$ fit well with the experimental spectra and were a sum of three different radical adducts (Figures 1c-e and $2 \mathrm{c}-\mathrm{e})$. On the basis of the hyperfine coupling constants obtained from the computer simulations, the adducts were assigned as follows: one carboncentered radical adduct (Figures $1 \mathrm{c}$ and $2 \mathrm{c}, a^{\mathrm{N}}=16.32$ $\mathrm{G}$ and $\left.a_{\beta}^{\mathrm{H}}=23.33 \mathrm{G}\right)$; oxygen-centered radical adduct 1 (Figures $1 \mathrm{~d}$ and $2 \mathrm{~d}$, DMPO/OR', $a^{\mathrm{N}}=$ $14.51 \mathrm{G}, a_{\beta}^{\mathrm{H}}=10.71 \mathrm{G}$, and $\left.a_{\gamma}^{\mathrm{H}}=1.32 \mathrm{G}\right)$, and oxygen-centered radical adduct 2 (Figure 1e, DMPO/ $\mathrm{OR}^{\prime \prime}, a^{\mathrm{N}}=14.86 \mathrm{G}$ and $a_{\beta}^{\mathrm{H}}=16.06 \mathrm{G}$ in the case of
t-BuOOH, and Figure 2e DMPO/OR", $a^{\mathrm{N}}=14.60 \mathrm{G}$ and $a_{\beta}^{\mathrm{H}}=15.61 \mathrm{G}$ in the case of $\left.\mathrm{CumOOH}\right)$. These two spectra of oxygen-centered radical adducts were previously assigned to $t$-butylperoxyl (cumylperoxyl), methylperoxyl, or methoxyl radical adducts and $t$-butyloxyl (cumyloxyl) radical adducts, respectively [11-20].

The relative contributions of those DMPO adducts to the composite ESR spectra in the reaction mixture containing $t$-BuOOH were different from those in the reaction mixture containing $\mathrm{CumOOH}$ as shown in 


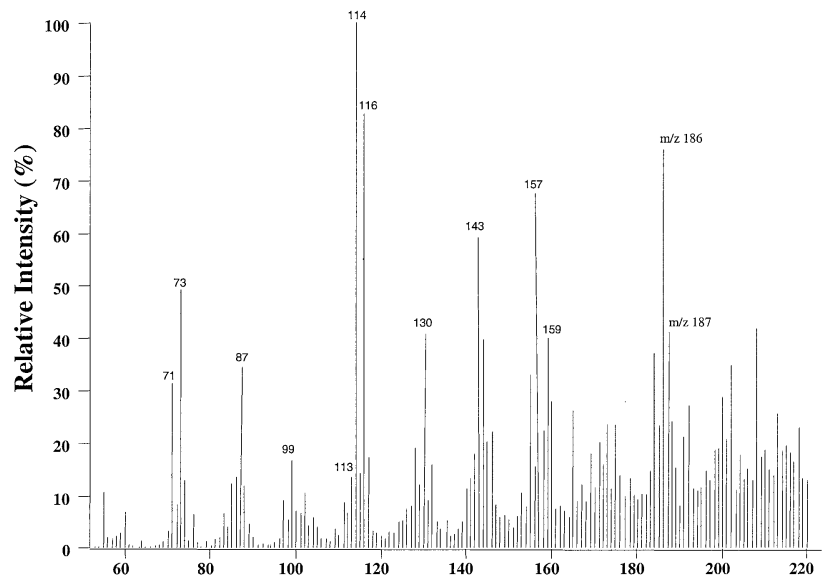

(a)

$\mathbf{m} / \mathbf{z}$

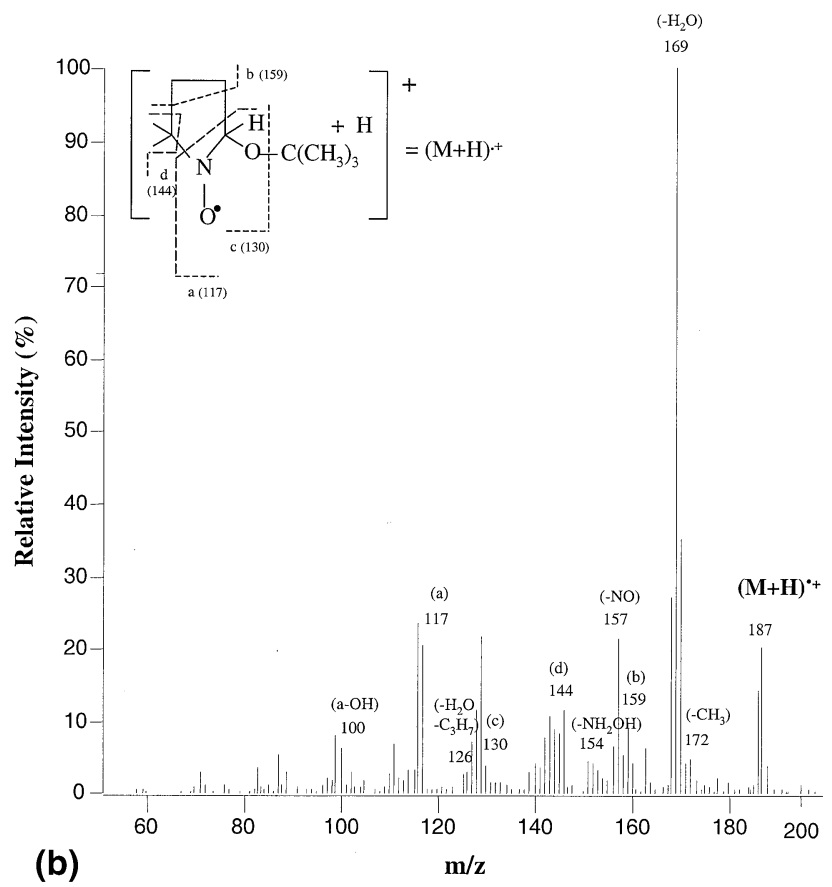

Figure 6. The ESI-MS (a) and MS/MS (b) spectra of the protonated molecule of DMPO/ OC $\left(\mathrm{CH}_{3}\right)_{3}$ adduct [(DMPO/OC $\left\{\mathrm{CH}_{3}\right\}_{3}+$ $\left.\mathrm{H})^{-+}, m / z=187\right]$ in the reaction of $\mathrm{Fe}^{2+}$ with $t$-butyl hydroperoxide. The analysis obtained from LC/ESR separation was infused into the mass spectrometer at $5 \mu \mathrm{L} / \mathrm{min}$ using a $500 \mu \mathrm{L}$ syringe associated with a syringe pump. Instrumental conditions are described in the Experimental section.

Figures 1 and 2. However, in each case, as the DMPO concentration was increased, the contribution of oxygen-centered radical adduct 1 (Figures $1 \mathrm{~d}$ and $2 \mathrm{~d}$ ) decreased, while the contribution of oxygen-centered radical adduct 2 (Figures 1e and 2e) increased (data not shown), consistent with previous reports $[16,17]$. Unlike the DMPO/oxygen-centered radical adducts, the DMPO/carbon-centered radical adduct was unstable and decayed rapidly with time (data not shown).
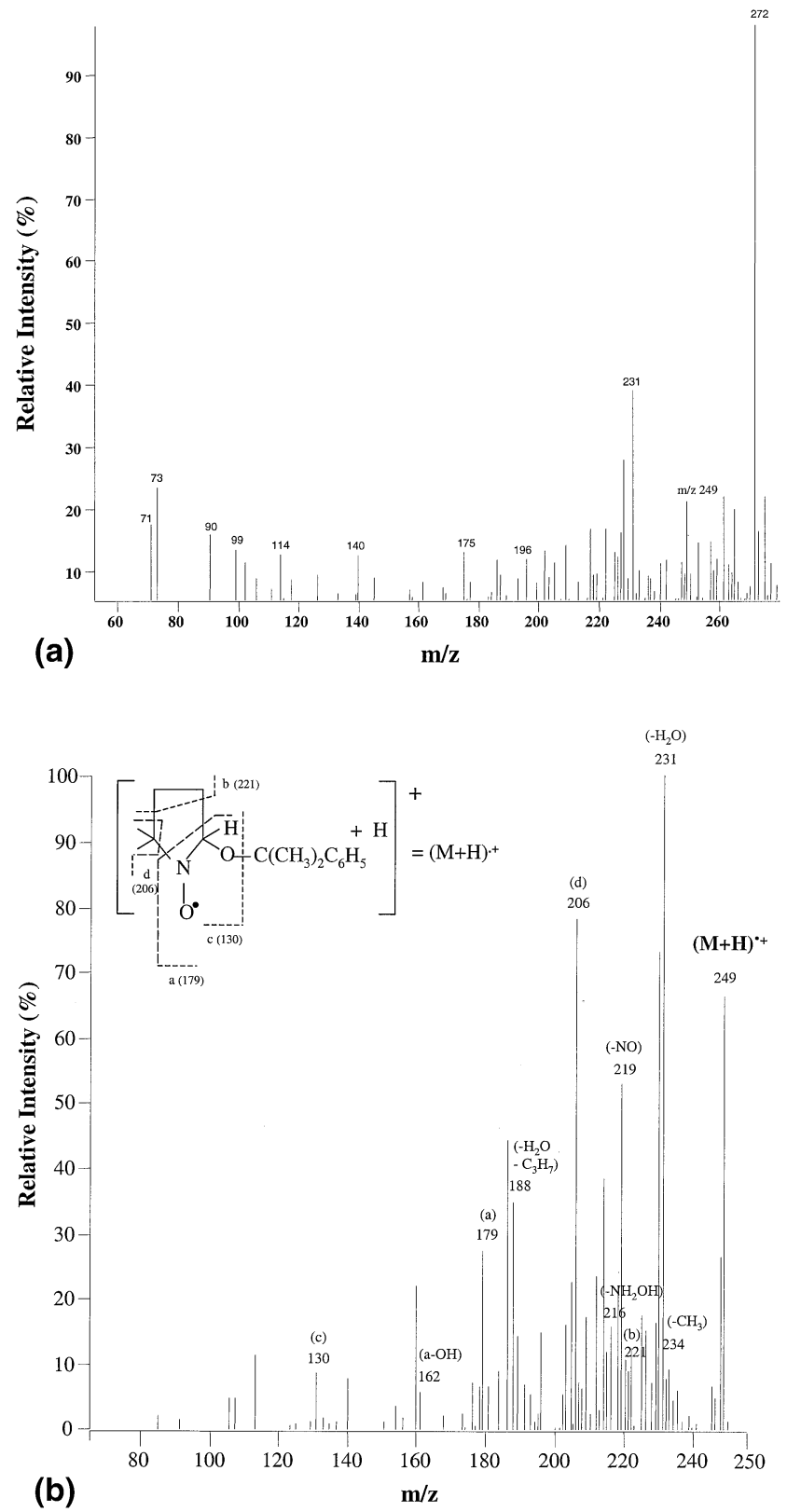

Figure 7. The ESI-MS (a) and MS/MS (b) spectra of the protonated molecule of DMPO/ $\mathrm{OC}\left(\mathrm{CH}_{3}\right)_{2} \mathrm{C}_{6} \mathrm{H}_{5}$ adduct [(DMPO/ $\left.\left.\mathrm{OC}\left\{\mathrm{CH}_{3}\right\}_{2} \mathrm{C}_{6} \mathrm{H}_{5}+\mathrm{H}\right)^{-+}, m / z=249\right]$ in the reaction of $\mathrm{Fe}^{2+}$ wit cumene hydroperoxide. The analysis obtained from LC/ESR separation was infused into the mass spectrometer at $5 \mu \mathrm{L} / \mathrm{min}$ using a $500 \mu \mathrm{L}$ syringe associated with a syringe pump. Instrumental conditions are described in the Experimental section.

\section{Separation of DMPO Radical Adducts Generated} from the Reaction of Organic Hydroperoxides with $\mathrm{Fe}^{2+}$

Since the above three DMPO radical adducts were assigned based on their hyperfine coupling constants, and their detailed structures were still unknown, separation and identification of those adducts was carried out in the following experiments.

The above reaction mixtures containing either $t$ - 

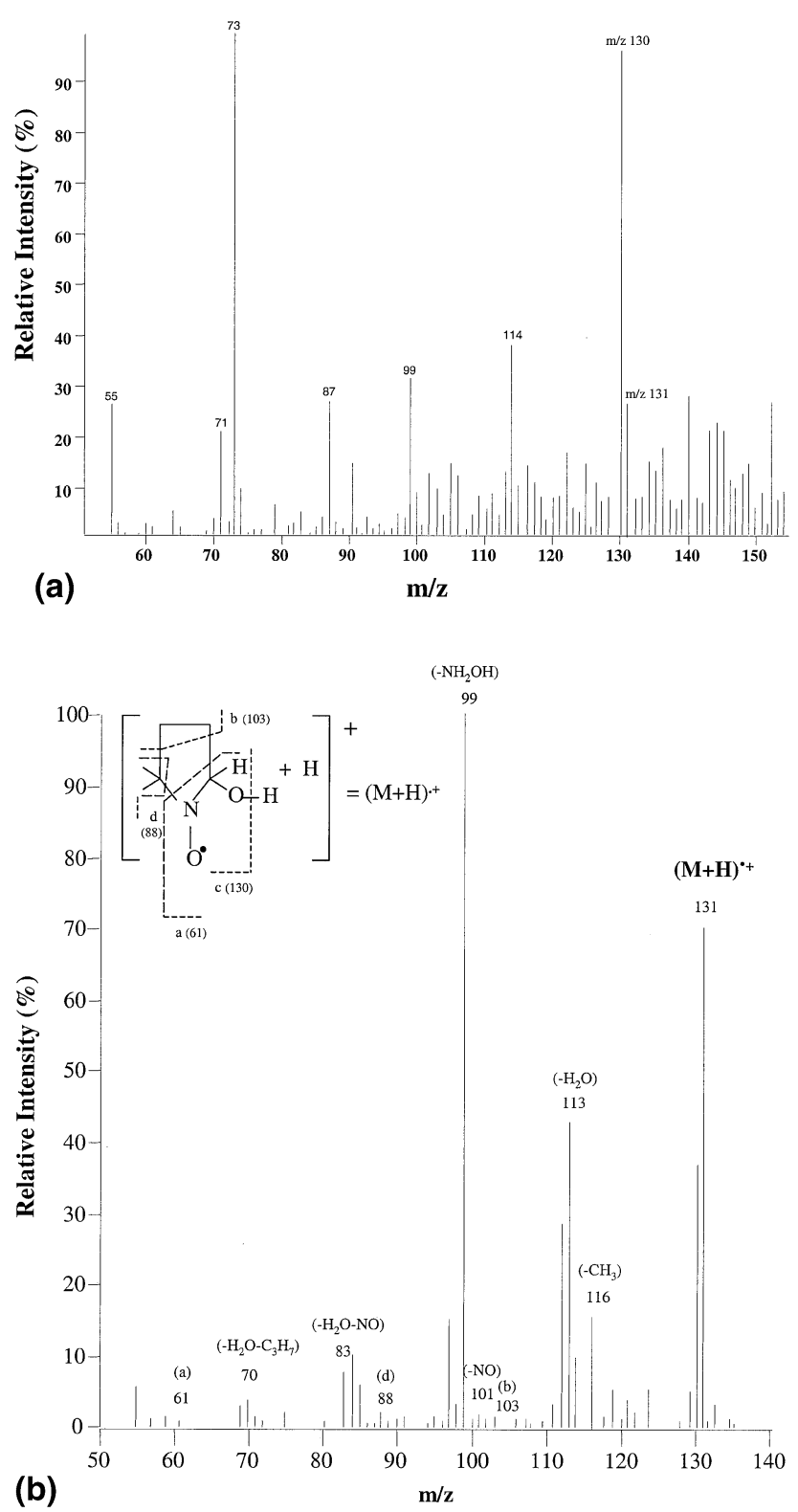

Figure 8. The ESI-MS (a) and MS/MS (b) spectra of the protonated molecule of DMPO/ $\mathrm{OH}$ adduct [(DMPO/OH $+\mathrm{H})^{-+}, \mathrm{m} / \mathrm{z}=$ 131] in the reaction of $\mathrm{Fe}^{2+}$ with $t$-butyl or cumene hydroperoxide. The analysis obtained from LC/ESR separation was infused into the mass spectrometer at $5 \mu \mathrm{L} / \mathrm{min}$ using a $500 \mu \mathrm{L}$ syringe associated with a syringe pump. Instrumental conditions are described in the Experimental section.

$\mathrm{BuOOH}$ or $\mathrm{CumOOH}$ were filtered and then injected onto an LC column to separate the DMPO adducts, which were monitored by both UV absorption and ESR. In each case, only two ESR-active adducts were separated and detected (Figures 3 and 4). During the first 12 min elution of the same mobile phase gradient, the first DMPO radical adduct (Peak 1 in Figures 3 and 4) from both systems exhibited identical chromatographic retention times $\left(t_{R}=9.6 \mathrm{~min}\right)$ and hyperfine coupling constants $\left(a^{\mathrm{N}}=14.51 \mathrm{G}, a^{\mathrm{H}}{ }_{\beta}=10.71 \mathrm{G}\right.$, and $a^{\mathrm{H}}{ }_{\gamma}=1.32$ $\mathrm{G})$, which are also identical to those of the first simulated oxygen-centered radical adducts as shown in
Figures $1 \mathrm{~d}$ and $2 \mathrm{~d}$. A peak with the same retention time and hyperfine coupling constants was also observed in a reaction system containing $10 \%$ methanol and $0.5 \mathrm{mM}$ $\mathrm{Fe}^{3+}$ in the presence of $50 \mathrm{mM}$ DMPO (data not shown); it has been previously shown that the DMPO/methoxyl radical adduct can be synthesized by mixing ferric ion with methanol in the presence of DMPO [19, 29, 30].

The second adduct (Peak 2 in Figures 3 and 4) was more non-polar in both cases: in the case of $t-\mathrm{BuOOH}$ it was eluted at $18.0 \mathrm{~min}$ (Peak 2 in Figure 3); for $\mathrm{Cu}$ $\mathrm{mOOH}$, it eluted at 21.1 min (Peak 2 in Figure 4), but only when a gradient with a more non-polar mobile phase was used after the first $12 \mathrm{~min}$. The hyperfine coupling constants of these two adducts were the same as those of oxygen-centered radical adduct 2 in Figures $1 \mathrm{e}$ and $2 \mathrm{e}$, respectively. Thus, these results showed that the DMPO oxygen-centered radical adducts were successfully separated and detected by online LC/ESR.

When subjected to LC separation, the carbon-centered radical adducts were not detected, presumably because they were too unstable. Thus, we cannot identify the carbon-centered radical adducts. Based on ESR spin trapping experiments using MNP as a spin trap, they have been identified as methyl, hydroxymethyl, and other carbon-centered radical adducts [13, 17].

In both reaction systems, when the DMPO concentration was doubled, the signal intensity of Peak 1 decreased but that of Peak 2 increased (data not shown). In addition, a new peak with the same retention time $(5.9 \mathrm{~min})$ was observed from both systems. Its retention time and hyperfine coupling constants were identical to those of the DMPO/hydroxyl radical adduct formed from a Fenton system containing $0.5 \mathrm{mM} \mathrm{H}_{2} \mathrm{O}_{2}$ and $0.5 \mathrm{mM} \mathrm{Fe}^{2+}$ in the presence of $12.5 \mathrm{mM}$ DMPO (data not shown).

\section{Identification of DMPO Radical Adducts Generated from the Reaction of Organic Hydroperoxides with $\mathrm{Fe}^{2+}$}

In order to identify the oxygen-centered DMPO adducts, the peaks of the corresponding adducts were collected just after elution from the UV detector and analyzed with ESI-MS and MS/MS. Figure $5 a$ and $5 b$ showed the ESI-MS and MS/MS spectra of Peak 1 in Figure 3, respectively. The MS/MS spectrum of Peak 1 in Figure 4 (data not shown) exhibited the same major fragment ions as those in Figure 5b. Since these two adducts also shared identical retention times and hyperfine coupling constants, this indicates that both DMPO adducts were from the same radical. Their protonated molecule, $\mathrm{m} / \mathrm{z} 145$, corresponded to that of the $\mathrm{DMPO} /$ methoxyl radical adduct, and all the major fragment ions in their MS/MS spectrum were consistent with the fragmentation pathways of the DMPO/ methoxyl radical adduct (Scheme 1). Therefore, this adduct of Peak 1 from both systems was derived from the methoxyl radical. This assignment was confirmed by the MS/MS spectrum of the DMPO/methoxyl rad- 
<smiles>[R]C1=[N+](O)C(C)(C)CC1</smiles>

Oxidized (protonated)

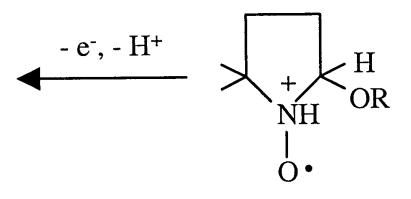

Radical (protonated)

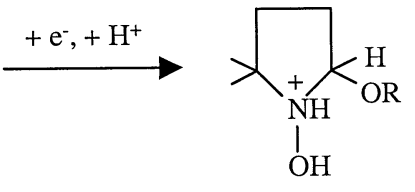

Reduced (protonated)

$$
\begin{array}{rlr}
\mathrm{R} & =\mathrm{H}: & \mathrm{m} / \mathrm{z} 130 \\
& =\mathrm{CH}_{3} & \mathrm{~m} / \mathrm{z} 144 \\
& =\mathrm{C}_{3}\left(\mathrm{CH}_{3}\right)_{3} & \mathrm{~m} / \mathrm{z} 186 \\
& =\mathrm{C}\left(\mathrm{CH}_{3}\right)_{2} \mathrm{C}_{6} \mathrm{H}_{5} & \mathrm{~m} / \mathrm{z} 248
\end{array}
$$

$\mathrm{m} / \mathrm{z} 132$

$\mathrm{m} / \mathrm{z} 146$

$\mathrm{m} / \mathrm{z} 188$

$\mathrm{m} / \mathrm{z} 250$

Scheme 2. Protonated molecules for the oxizided, radical, and reduced forms of DMPO oxygencentered radical adducts.

ical adduct synthesized from the methanol $/ \mathrm{Fe}^{3+}$ reaction system in this work (data not shown).

The protonated molecules (Figures $6 \mathrm{a}$ and $6 \mathrm{~b}$ and Figures $7 \mathrm{a}$ and $7 \mathrm{~b}$ ) of Peaks 2 in Figures 3 and 4, $m / z 187$ and $\mathrm{m} / \mathrm{z} 249$, corresponded to those of $\mathrm{DMPO} / \mathrm{t}$-butyloxyl and cumyloxyl radical adducts, respectively, and all the major fragment ions in their MS/MS spectra were consistent with the fragmentation pathways of $\mathrm{DMPO} / t$-butyloxyl and cumyloxyl radical adducts, respectively (Scheme 1). Thus, the corresponding adduct of Peak 2 from both systems was derived from the $t$-butyloxyl and cumyloxyl radicals, respectively.

The positive identification of these two radicals supports a previously suggested mechanism for the formation of the DMPO/methoxyl radical adduct [19]: $\mathrm{Fe}^{2+}$ reacts with $t$ - $\mathrm{BuOOH}$ (or $\mathrm{CumOOH}$ ) to produce the $t$-butyloxyl (or cumyloxyl) radical, which decomposes through $\beta$-scission into the methyl radical. The methyl radical reacts with oxygen to give the methyl peroxyl radical. Either DMPO reacts with methyl peroxyl radical to form $\mathrm{DMPO} /$ methylperoxyl radical adduct, which unstable and further decomposes to a secondary methoxyl radical trapped by DMPO, or the DMPO reacts directly with methoxyl radical formed from methyl peroxyl radical to give the DMPO/methoxyl radical adduct.

As mentioned above, the adduct corresponding to the additional peak at the high DMPO concentration showed the same retention time as the DMPO/hydroxyl radical adduct synthesized from the Fenton system. In addition, its protonated molecule, $\mathrm{m} / \mathrm{z} 131$, corresponded to that of the DMPO/hydroxyl radical adduct, and the major fragment ions in their MS/MS spectrum (Figure $8 \mathrm{~b}$ ) were the same as those found in the MS/MS spectrum of the synthesized DMPO/hydroxyl radical adduct in this work. Therefore, this adduct was from the DMPO/hydroxyl radical adduct. All the major fragment ions in their MS/MS spectrum were consistent with the fragmentation pathways of the DMPO/hydroxyl radical adduct (Scheme 1). This identification also supports the previous reports that a minor amount of hydroxyl radical was formed [13, 17], possibly from hydrogen peroxide present in the $t$ $\mathrm{BuOOH}$ or $\mathrm{CumOOH}$ solution as an impurity.
It was reported that POBN radical adducts were detected by MS in its oxidized protonated form [31], its radical protonated form [23-25], its reduced protonated form [22], or all of its three different protonated forms [32]. In addition, several previous studies showed that DMPO radical adducts were detected by MS in its oxidized protonated form [26, 28], its radical protonated form [27], or all of its three different protonated forms [32]. Therefore, in the present work, the collected ESR active DMPO radical adducts from LC-ESR experiments may be present in three different states during ESI-MS and MS/MS experiments: oxidized, radical and reduced protonated molecules (Scheme 2). However, as shown in Figures 5-8, comparable amounts of oxidized and radical protonated forms of DMPO radical adducts were observed. Those differences might be due to different properties of free radical adducts such as their redox properties and stability, different ionization modes such as ESI, fast-atom bombardment (FAB) and thermospray (TSP), and different MS experimental conditions used.

In summary, this study for the first time successfully used online LC/ESR to separate and detect oxygencentered radical adducts formed from the reaction of $\mathrm{Fe}^{2+}$ with $t-\mathrm{BuOOH}$ or $\mathrm{CumOOH}$. Furthermore, based on LC/ESR, ESI-MS and MS/MS analyses, this study provided direct evidence to prove that the previously reported DMPO/t-butylperoxyl and DMPO/cumylperoxyl adducts, which were later assigned as the $\mathrm{DMPO} /$ methylperoxyl and then the DMPO/methoxyl radical adduct, actually are the DMPO/methoxyl radical adduct. We have also confirmed the previous assignments of DMPO/ $t$-butyloxyl and cumyloxyl radical adducts with mass spectrometry, a direct and independent technique.

The breakdown of hydroperoxides of fatty acids by metal ions or the metaloproteins is thought to be of considerable biological importance. We are actively investigating the structures of DMPO oxygen-centered radical adducts produced by hydroperoxides of fatty acids. The methodological success in the separation and identification of DMPO oxygen-centered radical adducts formed from model organic hydroperoxides by iron using LC/ESR, ESI-MS and MS/MS may make it possible to directly identify the DMPO oxygen-centered 
radical adducts produced during peroxidation of fatty acids.

\section{Acknowledgments}

The authors are grateful to Dr. Jinjie Jiang for his technical help in the two-dimensional ESR scans and Dr. Ann Motten and Ms. Mary J. Mason for their valuable help in the preparation of this manuscript.

\section{References}

1. Gardner, L. J. Decomposition of Linoleic Acid Hydroperoxides. Enzymic Reactions Compared with Nonenzymic. J. Agric. Food Chem. 1975, 23, 129-136.

2. Marnett, L. J. Peroxyl Free Radicals: Potential Mediators of Tumor Initiation and Promotion. Carcinogenesis 1987, 8, 13651373.

3. Gutteridge, J. M. Free Radicals in Disease Processes: A Compilation of Cause and Consequence. Free Radic. Res. Commun. 1993, 19, 141-158.

4. Chandra, M.; Chandra, N.; Agrawal, R.; Kumur, A.; Ghatak, A.; Pandey, V.C. The Free Radical System in Ischemic Heart Disease. Int. J. Cardiol. 1994, 43, 121-125.

5. Dreher, D.; Junod, A. F. Role of Oxygen Free Radicals in Cancer Development. Eur. J. Cancer 1996, 32A, 30-38.

6. Knight, J. A. Free Radicals: Their History and Current Status in Aging and Disease. Annu. Clin. Lab. Sci. 1998, 28, 331-346.

7. Ashok, B. T.; Ali, R. The Aging Paradox: Free Radical Theory of Aging. Exp. Gerontol. 1999, 34, 293-303.

8. Chamulitrat, W.; Hughes, M. F.; Eling, T. E.; Mason, R. P. Superoxide and Peroxyl Radical Generation from the Reduction of Polyunsaturated Fatty Acid Hydroperoxides by Soybean Lipoxygenase. Arch. Biochem. Biophys. 1991, 290, 153-159.

9. Rota, C.; Barr, D. P.; Martin, M. V.; Guengerich, F. P.; Tomasi, A.; Mason, R. P. Detection of Free Radicals Produced from the Reaction of Cytochrome P-450 with Linoleic Acid Hydroperoxide. Biochem. J. 1997, 328, 565-571.

10. Qian, S. Y.; Wang, H. P.; Schafer, F. Q.; Buettner, G. R. EPR Detection of Lipid-Derived Free Radicals from PUFA, LDL, and Cell Oxidations. Free Radic. Biol. Med. 2000, 29, 568-579.

11. Davis, M. J. Detection of Peroxyl and Alkoxyl Radicals Produced by Reaction of Hydroperoxides with Heme-Proteins by Eletron Spin Resonance Spectroscopy. Biochim. Biophys. Acta 1988, 964, 28-35.

12. Davies, M. J. Detection of Peroxyl and Alkoxyl Radicals Produced by Reaction of Hydroperoxides with Rat Liver Microsomal Fractions. Biochem. J. 1989, 257, 603-606.

13. Chamulitrat, W.; Takahashi, N.; Mason, R. P. Peroxyl, Alkoxyl, and Carbon-Centered Radical Formation from Organic Hydroperoxides by Chloroperoxidase. J. Biol. Chem. 1989, 264, 7889-7899.

14. Kennedy, C. H.; Church, D. F.; Winston, G. W.; Pryor, W. A. Tert-Butyl Hydroperoxide-Induced Radical Production in Rat Liver Mitochondria. Free Radic. Biol. Med. 1992, 12, 381-387.

15. Akaike, T.; Sato, K.; Ijiri, S.; Miyamoto, Y.; Kohno, M.; Ando, M.; Maeda, H. Bactericidal Activity of Alkyl Peroxyl Radicals Generated by Heme-Iron-Catalyzed Decomposition of Organic Peroxides. Arch. Biochem. Biophys. 1992, 294, 55-63.

16. Barr, D. P.; Mason, R. P. Mechanism of Radical Production from the Reaction of Cytochrome c with Organic Hydroperoxides: An ESR Spin Trapping Investigation. J. Biol. Chem. 1995, 270, 12709-12716.

17. Barr, D. P.; Martin, M. V.; Guengerich, F. P.; Mason, R. P. Reaction of Cytochrome P450 with Cumene Hydroperoxide:
ESR Spin-Trapping Evidence for the Homolytic Scission of the Peroxide O-O Bond by Ferric Cytochrome P450 1A2. Chem. Res. Toxicol. 1996, 9, 318-325.

18. Van der Zee, J.; Barr, D. P.; Mason, R. P. ESR Spin Trapping Investigation of Radical Formation from the Reaction between Hematin and tert-Butyl Hydroperoxide. Free Radic. Biol. Med. 1996, 20, 199-206.

19. Dikalov, S. I.; Mason, R. P. Reassignment of Organic Peroxyl Radical Adducts. Free Radic. Biol. Med. 1999, 27, 864-872.

20. Dikalov, S. I.; Mason, R. P. Spin Trapping of Polyunsaturated Fatty Acid-Derived Peroxyl Radicals: Reassignment to Alkoxyl Radical Adducts. Free Radic. Biol. Med. 2001, 30, 187-197.

21. Iwahashi, H.; Albro, P. W.; McGown, S. R.; Tomer, K. B.; Mason, R. P. Isolation and Identification of $\alpha$-(4-Pyridyl-1Oxide)-N-tert-Butylnitrone Radical Adducts Formed by the Decomposition of the Hydroperoxides of Linoleic Acid, Linolenic Acid, and Arachidonic Acid by Soybean Lipoxygenase. Arch. Biochem. Biophys. 1991, 285, 172-180.

22. Iwahashi, H.; Deterding, L. J.; Parker, C. E.; Mason, R. P.; Tomer, K. B. Identification of Radical Adducts Formed in the Reactions of Unsaturated Fatty Acids with Soybean Lipoxygenase Using Continuous Flow Fast Atom Bombardment with Tandem Mass Spectrometry. Free Radic. Res. 1996, 25, 255-274.

23. Iwahashi, H. Some Polyphenols Inhibit the Formation of Pentyl Radical and Octanoic Acid Radical in the Reaction Mixture of Linoleic Acid Hydroperoxide with Ferrous Ions. Biochem. J. 2000, 346, 265-273.

24. Iwahashi, H.; Nishizaki, K.; Takagi, I. Cytochrome $c$ Catalyses the Formation of Pentyl Radical and Octanoic Acid Radical from Linoleic Acid Hydroperoxide. Biochem. J. 2002, 361, 57-66.

25. Qian, S. Y.; Tomer, K. B.; Yue, G-H.; Guo, Q.; Kadiiska, M. B.; Mason, R. P. Characterization of the Initial Carbon-Centered Pentadienyl Radical and Subsequent Radicals in Lipid Peroxidation: Identification via On-Line High Performance Liquid Chromatography/Electron Spin Resonance and Mass Spectrometry. Free Radic. Biol. Med. 2002, 33, 998-1009.

26. Iwahashi, H.; Parker, C. E.; Mason, R. P.; Tomer, K. B. Radical Identification by Liquid Chromatography/Thermospray Mass Spectrometry. Rapid Commun. Mass Spectrom. 1990, 4, 352-354.

27. Krainev, A. G.; Williams, T. D.; Bigelow, D. J. OxygenCentered Spin adducts of 5,5-Dimethyl-1-PyrrolineN-Oxide (DMPO) and 2H-Imidazole 1-Oxides. J. Mag. Reson. B 1996, 111, 272-280.

28. Domingues, P.; Domingues, M. R. M.; Amado, F. M. L.; Ferrer-Correia, A. J. Detection and Characterization of Hydroxyl Radical Adducts by Mass Spectrometry. J. Am. Soc. Mass Spectrom. 2001, 12, 1214-1219.

29. Hanna, P. M.; Chamulitrat, W.; Mason, R. P. When Are Mental Ion-Dependent Hydroxyl Radical and Alkoxyl Radical Adducts of 5,5-Dimethyl-1-Pyrroline N-Oxide Artifacts? Arch. Biochem. Biophys. 1992, 296, 640-644.

30. Makino, K.; Hagiwara, T.; Hagi, A.; Nishi, M.; Murakami, A. Cautionary Note for DMPO Spin Trapping in the Presence of Iron Ion. Biochem. Biophys. Res. Commun. 1990, 172, 1073-1080.

31. Qian, S. Y.; Chen, Y. R.; Deterding, L. J.; Fann, Y. C.; Chignell, C. F.; Tomer, K. B.; Mason, R. P. Identification of ProteinDerived Tyrosyl Radical in the Reaction of Cytochrome c and Hydrogen Peroxide: Characterization by ESR Spin-Trapping, HPLC and MS. Biochem. J. 2002, 363, 281-288.

32. Iwahashi, H.; Parker, C. E.; Mason, R. P.; Tomer, K. B. Combined Liquid Chromatography/Electron Paramagnetic Resonance Spectrometry/Electrospray Ionization Mass Spectrometry for Radical Identification. Anal. Chem. 1992, 64, $2244-2252$. 